\title{
PERITONEAL GRAFT IN EXTREMELY RETRACTED CONJUNCTIVAL SAC*
}

\author{
BY \\ SELAHATTIN ERBAKAN $\dagger$ \\ Izmir, Turkey
}

VARIOUS mucosal and skin materials have been used in plastic operations on the conjunctiva, and the mucosa of the mouth and lips have been found most suitable. Apart from these materials, the Thiersch graft, part of the peritoneal membrane, the rectum, the preputium, and the labia minora have also been used for small conjunctival defects.

Sorsby and Symons (1946) found amniotic membrane suitable in the reconstruction of large defects. Allen (1953) used autografts from the abdominal peritoneum. Malhotra (1957) recommended peritoneum, taken from inguinal hernias, as a routine procedure in entropion surgery. Erbakan (1958) successfully used a peritoneal graft taken from an inguinal hernia, in the case of a large naevus showing signs of malignancy, which was situated in the lower fornix and partly involved the bulbar conjunctiva.

In the following three cases a peritoneal graft was used to enlarge the retracted conjunctival sac into which a prosthesis could not be inserted.

\section{Case Reports}

Case 1, a housewife aged 49, had had the right eye enucleated 30 years ago. She had not been able to wear her prosthesis for the last 6 months because of the retracted conjunctival sac. She complained of not being able to insert any prosthesis of any size.

Examination revealed a completely fiattened lower fornix and a retracted socket which could not retain even the smallest type of prosthesis.

On July 10, 1958, a plastic operation was performed to enlarge the upper and lower fornices, using a peritoneal graft taken from an inguinal hernia. After the operation, she was able to wear her prosthesis very well (Figs 1 and 2, opposite).

Case 2, a tradesman aged 48, had been blind in the right eye since he was 2 years old, and the eye had been enucleated when he was aged 16. For more than 4 years he had not been able to wear a prosthesis, and 3 months previously (in another city) a plastic operation had been done to enlarge the retracted conjunctival sac but without success.

Examination showed flattened and retracted upper and lower fornices with no room for even the smallest prosthesis.

* Received for publication September 9, 1959.

$\dagger$ Assistant Professor in the Department of Ophthalmology, Hospital of the University of Ege and the General Hospital of Izmir. 

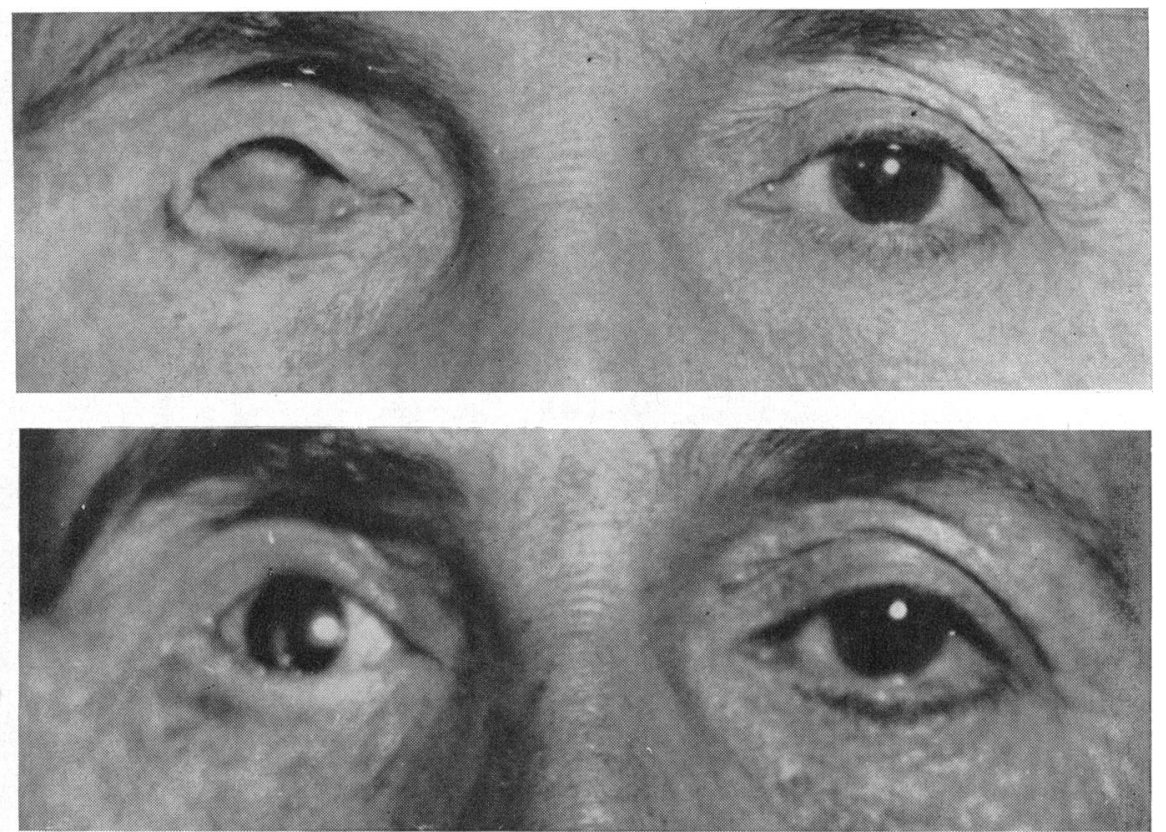

Figs 1 and 2.-Case 1, before and after operation to right socket.

In September, 1958, an operation was done to enlarge the upper and lower fornices, using a free peritoneal graft. The patient is now able to wear a relatively large prosthesis (Figs 3 and 4).
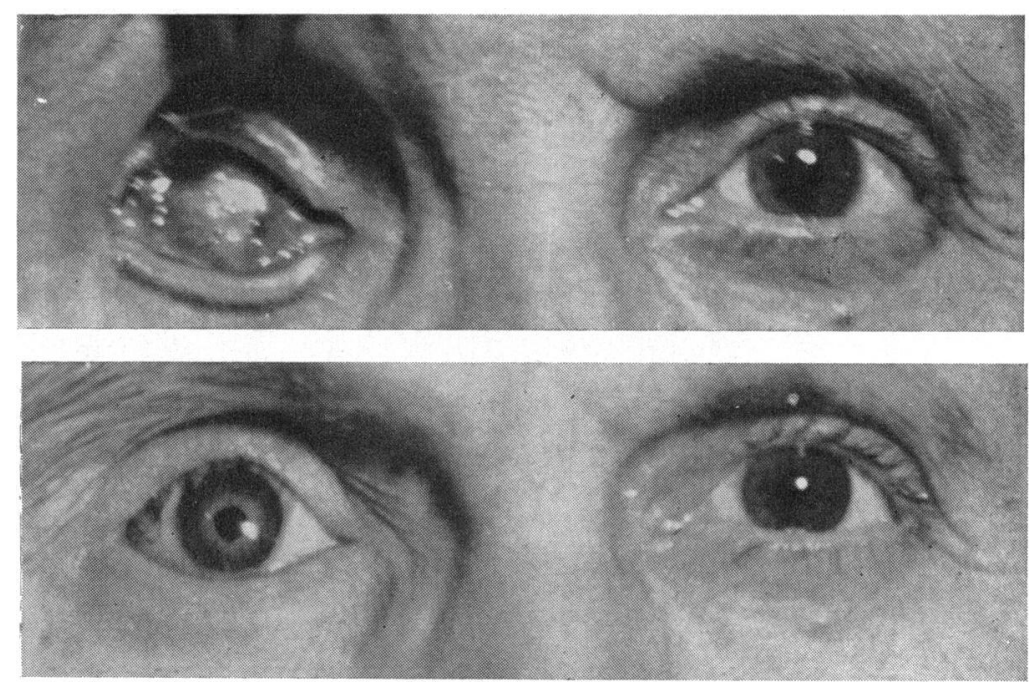

Figs 3 and 4.- Case 2, before and after operation to right socket.

Case 3, a farmer aged 25, had had his left eye enucleated after an injury when he was 5 years old. He did not wear any prosthesis, and when he was examined in the 
out-patient department, it was impossible to insert any prosthesis of any size, because of an extremely retracted conjunctival sac.

On February 3, 1959, a plastic operation was performed to enlarge the conjunctival sac, using a peritoneal graft. The result is shown in Figs 5 and 6.
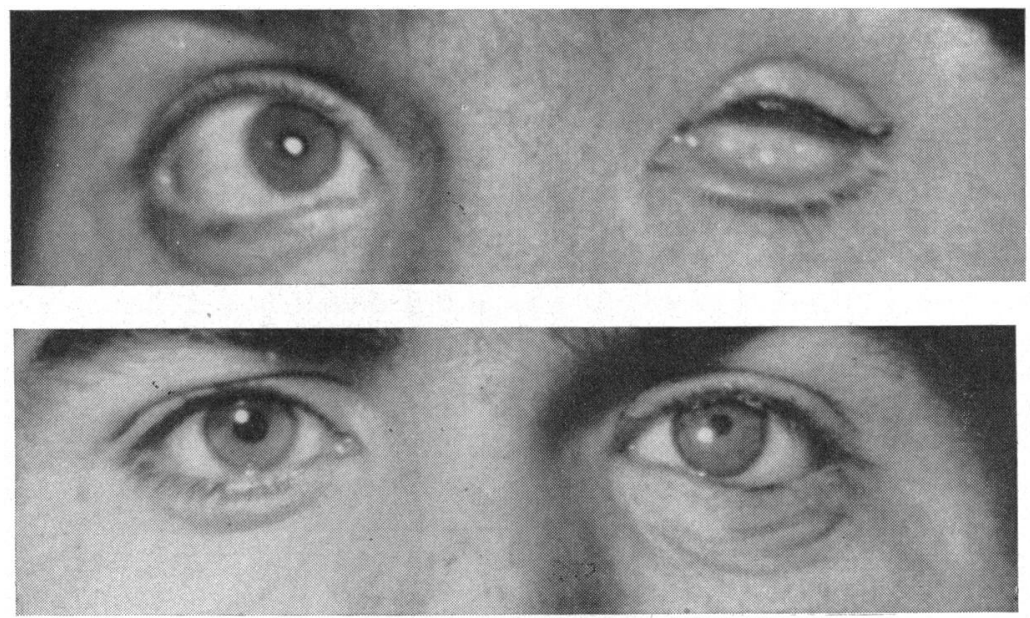

Figs 5 and 6.-Case 3, before and after operation to left socket.

\section{Technique}

Two horizontal incisions are made, one beginning from the lateral canthus to the medial canthus and the second in the middle of the conjunctival sac. The first incision is dissected and deepened until it reaches the lower orbital margin. The upper part of the second incision is dissected up to the upper fornix. Thus, the upper part of the conjunctiva is left for the reconstruction of the upper fornix. The graft, taken from hernia peritoneum, is placed like a pocket in the dissected lower area. At the bottom of the pocket three Snellen sutures are inserted. A second piece of peritoneal graft is then apposed to the oval defect of the conjunctiva which is produced by pushing the upper part of conjunctiva.

The prosthesis is inserted in the new large sac and a tarsorrhaphy is carried out. The whole orbit is left under a pressure bandage for a long time (Figs 7, 8, 9 and 10).

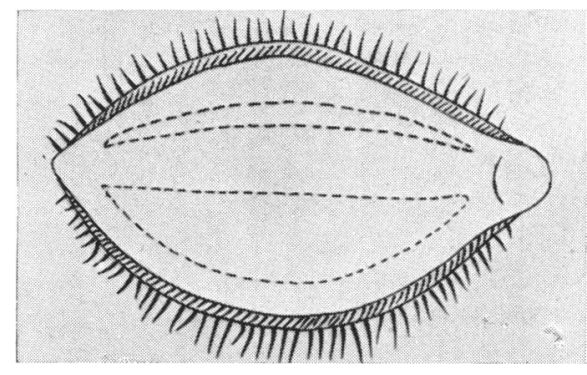

FIG. 7

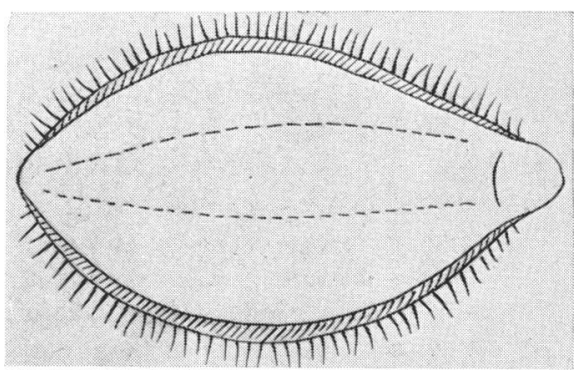

FIG. 8 


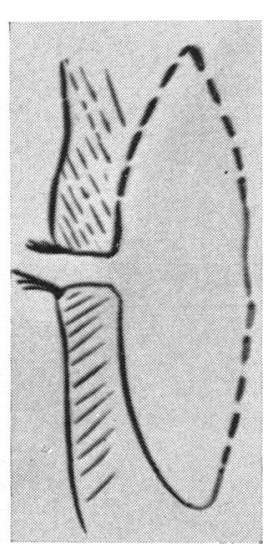

Fig. 9

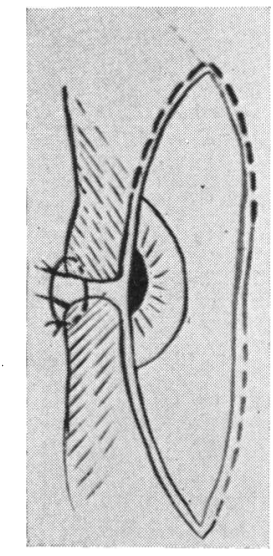

Fig. 10

FIGs 7, 8, 9, 10.-Stages in the enlargement of the socket by means of a peritoneal graft.

\section{Conclusion}

A peritoneal graft for the enlargement of a retracted conjunctival sac gives very satisfactory results, but there appears to be no reference in the current literature and surgical text-books to the use of a peritoneal graft for this purpose.

\section{REFERENCES}

Allen, J. H. (1953). Amer. J. Ophthal., 36, 1249.

ERBAKAN, S. (1958). Göz Klin. (Istanbul), 4, 2.

MALHOTRA, M. (1957). Brit. J. Ophthal., 41, 616.

SORSBY, A., and SYMONS, H. M. (1946). Ibid., $30,337$. 